\title{
ANALISIS PENDAPATAN USAHA PRODUK NIRA DI DESA LOLAH KECAMATAN TOMBARIRI TIMUR
}

\author{
Mersya Thesalonika Terok \\ O. Esry H. Laoh \\ Benu Olfie L. S
}

\begin{abstract}
The purpose of this research is to know the total income of sap from palm sugar (nira) product is income from brown sugar processing and traditional beverage (captikus) in Lolah Village, East Tombariri Subdistrict, Minahasa Regency. This research was conducted for two months, from June to July 2017. The data used are primary data obtained through interviews to 20 entrepreneurs of palm sugar consisting of 2 brown sugar businessmen and 18 traditional beverage (captikus) entrepreneurs and secondary data obtained from Lolah Village Office. The analysis used is income analysis. The results showed that the production of palm juice in Lolah Village was processed into brown sugar and captikus with average monthly income from brown sugar business Rp.2.724.446 and from captikus production amounted to Rp.3.572.751. The total income per month of the production of sap from palm sugar can be obtained by adding the income of brown sugar and captikus which is Rp.6.297.197.-
\end{abstract}

Keywords: income analysis, sap from palm sugar tree, Lolah Village, East Tombariri Subdistrict, Minahasa Regency

\begin{abstract}
ABSTRAK
Penelitian ini bertujuan untuk mengetahui besarnya pendapatan total produk nira yaitu pendapatan yang berasal dari pengolahan gula merah dan captikus di Desa Lolah Kecamatan Tombariri Timur, Kabupaten Minahasa. Penelitian ini dilaksanakan selama dua bulan yaitu dari bulan Juni sampai bulan Juli 2017. Data yang digunakan adalah data primer yang diperoleh melalui wawancara kepada 20 pengusaha nira aren yang terdiri atas 2 pengusaha gula merah dan 18 pengusaha captikus dan data sekunder diperoleh dari Kantor Desa Lolah. Analisis yang digunakan yaitu analisis pendapatan. Hasil penelitian menunjukkan bahwa produksi nira aren di Desa Lolah yang diolah menjadi gula merah dan captikus dengan rata-rata pendapatan per bulan dari usaha gula merah sebesar Rp.2.724.446 dan dari produksi captikus sebesar Rp.3.572.751. Jumlah keseluruhan pendapatan total hasil produksi nira dapat diperoleh dengan menambahkan hasil produksi gula merah dan captikus yaitu sebesar Rp.6.297.197.- dalam satu bulan.
\end{abstract}

Kata Kunci: analisis pendapatan, produk nira, Desa Lolah, Kecamatan Tombariri Timur, Kabupaten Minahasa 


\section{PENDAHULUAN}

\section{Latar Belakang}

Pertanian merupakan salah satu kekayaan yang dimiliki oleh Bangsa Indonesia dan memegang peranan penting dalam perekonomian di Indonesia. Pertanian Indonesia khususnya di Sulawesi Utara memiliki banyak potensi yang dapat diolah dan dimanfaatkan. Salah satu keunggulan yang dimiliki Sulawesi Utara adalah pohon Aren (Arenga pinnata MERR) atau Enau dalam Lasut, 2012 termasuk suku palem-paleman yang memiliki berbagai fungsi antara lain fungsi konservasi dan fungsi ekonomis, sebab hampir semua bagian tanaman akar, batang, daun, buah dapat dimanfaatkan untuk berbagai keperluan manusia.

Tanaman enau banyak ditemukan tumbuh secara liar pada daerah perbukitan dan lembah, dan berkembang tanpa dibudidayakan (Istino, 2015). Tanaman aren merupakan jenis tanaman tahunan, berukuran besar, berbentuk pohon soliter tinggi hingga $12 \mathrm{~m}$, diameter setinggi dada hingga $60 \mathrm{~cm}$ (Tambayong, 2016). Tanaman aren bertumbuh dengan ketinggian $500-1.200 \mathrm{~m}$ dari permukaan laut. Tumbuh baik pada tanah gembur, tanah vulkanis, dan tanah berpasir di tepian sungai. Pada iklim yang sesuai tanaman ini dapat mencapai umur 15 - 20 tahun (Lasut, 2012)

Pohon Aren atau Enau ini lebih dikenal oleh masyarakat Sulawesi Utara adalah pohon Seho yang dapat menghasilkan nira aren yang dikenal masyarakat Minahasa adalah 'Saguer'. Masyarakat pada umumnya sudah lama memanfaatkan tanaman ini dari hasil nira aren, yang dapat langsung di konsumsi atau diminum air niranya dapat juga diolah menjadi gula merah atau gula batu yang banyak dikenal masyarakat juga nira aren dapat menjadi asam cuka, lebih khusus nira aren diolah dan menjadi produksi captikus. Sebagian besar masyarakat petani yang ada bermata pencaharian dari pohon aren atau enau yang pada umumnya mengambil hasil nira arennya.

Banyaknya pohon enau, maka masyarakat Minahasa memanfaatkan hasil nira arennya menjadi dua produksi yaitu gula merah dan captikus, salah satunya masyarakat petani di Desa Lolah Kecamatan Tombariri Timur Kabupaten Minahasa desa ini mempunyai hutan atau kebun yang diberi nama Tatawiran yang pada umumya masyarakat memanfaatkannya banyak hasil yang diperoleh dari hutan atau kebun tersebut terutama pohon aren atau enau 'seho' banyak tersebar di kawasan hutan atau kebun Tatawiran.

Tanaman ini pula dapat bertumbuh, berkembang dengan baik sehingga dapat menghasilkan dan dijadikan petani untuk diolah nira 'saguer' menjadi gula merah dan captikus sebagai usaha produksi terutama masyarakat petani di Desa Lolah menjadikan dua produksi ini menjadi usaha petani yang telah menjadi mata pencahariannya. Memanfaatkan hasil nira aren masyarakat pengelolah produksi ini mendapatakan keuntungan dan dapat memperbaiki kehidupan masyarakatnya yaitu bisa menghidupi keluarga, menyekolakan anak, membangun rumah,dan menambah modal usaha.

Produksi Gula merah juga menjadi hasil produksi dari nira aren sehingga dimanfaatkan menjadi produk hasil yang bernilai ekonomis sebagian membuat gula merah sebagai mata pencaharian yang cukup baik bagi petani karena hasil gula merah menguntungkan bagi petani pembuat gula merah. Pengolahan gula merah bagi masyarakat di Desa Lolah masih menggunakan cara tradisional pada umumnya. Nira aren yang diambil sudah memiliki kandungan gula yang tinggi dan diolah yaitu dimasak selama 5-6 jam, untuk menetukan manisnya gula merah ini yaitu pada saat penyadapan nira aren, dengan penyadapan yang sesuai dan baik maka akan memperoleh hasil nira aren yang manis dan sesuai.

Minuman beralkohol captikus ini dibuat sendiri oleh masyarakat minahasa dengan cara tradisional sehingga captikus ini disebut sebagai minuman tradisional khas minahasa. masyarakat Minahasa sudah lama dikenal sebagai wilayah penghasil usaha produksi captikus yang termasuk besar di Sulawesi Utara. Captikus adalah jenis cairan yang diolah dari nira aren lalu dimasak sampai keluar cairan hasil penyulingan menjadi minuman beralkohol yang berkadar 34-38 \% tinggi rendahnya kadar alcohol cap tikus dapat berpengaruh pula pada nira aren 'saguer' yang keluar ataupun rasanya baik itu manis ataupun asam, terlebih mayang 
yang mengeluarkan nira aren yang harus bersih. Kadar alkohol dapat juga diukur ketika sedang memasaknya, maka kualitasnya akan memperoleh hasil yang sesuai ataupun baik.

Usaha produk nira aren di Desa Lolah, harga sangatlah berperan penting dalam meningkatkan kesejahteraan petani. Harga ini yang menjadikan faktor dimana petani di desa ini masih tetap bertahan untuk mengusahakan produksi nira aren, sehingga secara tidak langsung dapat meningkatkan pendapatan petani itu sendiri.

Pendapatan dipengaruhi oleh beberapa faktor antara lain harga jual produk, biaya produksi penjualan. Tujuan dari usaha adalah untuk memperoleh pendapatan setinggitingginya bagi masyarakat petani, besarnya pendapatan ini dapat digunakan untuk menilai keberhasilan petani dalam mengelolanya

\section{Rumusan Masalah}

Berdasarkan latar belakang maka yang dirumuskan masalah adalah berapa besar pendapatan produk nira di Desa Lolah Kecamatan Tombariri Timur.

\section{Tujuan Penelitian}

Penelitian ini bertujuan untuk mengetahui besarnya pendapatan produk nira yaitu gula merah dan captikus di Desa Lolah Kecamatan Tombariri Timur.

\section{Manfaat Penelitian}

Manfaat dari hasil penelitian ini diharapkan dapat menjadi bahan masukkan bagi pemerintah, pengusaha, petani dan peneliti juga sebagai bahan informasi.

\section{METODOLOGI PENELITIAN}

\section{Waktu dan Tempat Penelitian}

Penelitian ini berlangsung selama dua Bulan dari Bulan Juni 2017 sampai Bulan Juli 2017mulai dari persiapan sampai dalam penyusunan laporan. Penelitian ini dilakukan di Desa Lolah Kecamatan Tombariri Timur.

\section{Metode Pengumpulan Data}

Data yang akan digunakan dalam penelitian ini adalah data primer dan data sekunder. Data primer diperoleh melalui metote wawancara secara langsung dengan responden menggunakan daftar pertanyaan (kuisioner) dan pengamatan secara langsung pada pengolah usaha produk nira di Desa Lolah.

Data sekunder dapat diperoleh dari istansi yang terkait dari penelitian ini.

\section{Metode Pengambilan Sampel}

Menggunakan metode "purposive sampling" yaitu pengambilan sampel secara sengaja yang diambil sebanyak 18 pengolah captikus dan 2 pengolah gula merah yang diambil secara keseluruhan, karena pengolah hanya dua.

\section{Konsepsi Pengukuran Variabel}

Variabel yang akan diukur dalam penelitian ini adalah:

1. Pendapatan produk nira (perbulan)

2. Harga jual produksi nira (Rp)

3. Biaya produksi nira (Rp)

4. Biaya yang dikeluarkan oleh pengolah untuk memproduksi nira yaitu biaya penyusutan alat dan transportasi

\section{Metode Analisis Data}

Analisis data yang digunakan dalam penenlitian ini adalah analisis data secara deskriptif. Sedangkan untuk mengetahui pendapatan usaha produk nira menggunakan analisis pendapatan usaha. Pendapatan adalah selisih antara penerimaan dengan pengeluaran total usaha cap tikus.

Pendapatan dirumuskan sebagai berikut :

Rumus:

$$
\text { Pd }=\text { TR }- \text { TC }
$$

Dimana:

$$
\begin{aligned}
& \mathrm{Pd}=\text { Pendapatan usaha tani } \\
& \mathrm{TR}=\text { Total Penerimaan } \\
& \mathrm{TC}=\text { Total Biaya }
\end{aligned}
$$

Analisis Biaya UsahaUntuk mengetahui besarnya biaya produksi yang digunakan dalam proses produksi usaha cap tikus menggunakan rumus :

$$
\mathbf{T C}=\mathbf{T F C}+\mathbf{T V C}
$$

Dimana :

TC $($ Total cost $)=$ Total biaya $(\mathrm{Rp})$

TFC $($ Total fied cost $)=$ total biaya tetap $(\mathrm{Rp})$

TVC $($ Total Variable cost $)=$ total biaya variabel 
Menghitung biaya penyusutan

Dimana :

$$
D=\frac{P-S}{N}
$$

$\mathrm{D}=$ biaya penyusutan $(\mathrm{Rp})$

$\mathrm{P}=$ harga awal $(\mathrm{Rp})$

$\mathrm{S}=$ harga akhir mesin (Rp)

$\mathrm{N}=$ umur ekonomis (bulan)

Analisis Penerimaan Usaha analisis data yang digunakan dalam penelitian ini adalah analisis pendapat usaha pengelohan cap tikus. Untuk mengetahui besar tingkat penerimaan yang diperoleh dapat menggunakan rumus :

$$
\mathbf{T R}=\mathbf{P} \mathbf{X} \mathbf{Q}
$$

Dimana :

TR $($ Total Revenue $)=$ Total Penerimaan

$\mathrm{P}($ Price $)=$ Harga Produk $(\mathrm{Rp})$

$\mathrm{Q}($ Quantity $)=$ Jumlah Produk (Unit)

\section{HASIL DAN PEMBAHASAN}

\section{Deskripsi Daerah Penelitian}

\section{Letak Wilayah}

Desa Lolah terletak di Kecamatan Tombariri Timur Kabupaten Minahasa Provinsi Sulawesi Utara. Luas Desa Lolah 4.820 Ha. Jarak dengan Ibukota Kabupaten/kota $25 \mathrm{Km}$. Desa Lolah berada pada ketinggian $200 \mathrm{Mdpl}$ (meter diatas permukaan laut). Batas - batas wilayah sebagai berikut :

1. Sebelah Utara dengan Perkebunan Desa Lemoh

2. Sebelah Timur dengan pengunungan Tatawiran

3. Sebelah Selatan dengan Desa Ranotongkor

4. Sebelah Barat dengan Desa Lemoh

\section{Keadaan Penduduk}

Total keseluruhan jumlah penduduk yang berdomisili di Desa Lolah adalah sebanyak 4046 Jiwa yang terdiri atas Laki-laki 2052 jiwa dan Perempuan 1994 Jiwa.

\section{Karakteristik Responden}

Umur akan dapat mempengaruhi kemampuan seseorang untuk bekerja secara fisik maupun dalam menentukan cara berpikir,dan umumnya kemampuan seseorang yang lebih muda kerjanya lebih lama. Umur produktif pada usia 15 tahun sampai 60 tahun. Menurut hasil penelitian yang sudah dilakukan umur responden dapat dilihat pada Tabel 1 .

Tabel 1. Jumlah Responden Menurut Tingkat Umur

\begin{tabular}{ccccc}
\hline \multirow{2}{*}{$\begin{array}{c}\text { Umur } \\
\text { (Tahun) }\end{array}$} & \multicolumn{4}{c}{ Jumlah Responden } \\
\cline { 2 - 5 } & Captikus & $\%$ & $\begin{array}{c}\text { Gula } \\
\text { Merah }\end{array}$ & $\%$ \\
\hline $40-50$ & 12 & 66,67 & 2 & 100,00 \\
$51-60$ & 6 & 33,33 & - & - \\
\hline Jumlah & 18 & 100,00 & 2 & 100,00 \\
\hline \multicolumn{5}{c}{ Pada tabel 1 } \\
\hline
\end{tabular}
responden sebagian besar memiliki umur produktif yaitu umur 40-50 tahun berjumlah untuk pengusaha cap tikus 12 orang atau 66,67 dan pengusaha gula merah 2 dengan presentase 100,00 .

\section{Tingkat Pendidikan Responden}

Tingkah laku individu atau seseorang sangat dipengaruhi oleh pendidikan yang telah dicapai. Peran pendidikan formal sangat penting dalam usaha peningkatan kualitas penduduk serta peningkatan intelektual serta wawasan seseorang. Berdasarkan hasil penelitian, tingkat pendidikan responden sangat bervariasi. Hal tersebut dapat dilihat pada Tabel 2.

\section{Tabel 2. Tingkat Pendidikan Petani} Menurut Jumlah Responden

\begin{tabular}{clrc}
\hline \multirow{2}{*}{ No } & \multirow{2}{*}{$\begin{array}{c}\text { Tingkat } \\
\end{array}$} & Pendidikan & \multicolumn{2}{c}{$\begin{array}{c}\text { Jumlah Responden } \\
\text { (Orang) }\end{array}$} \\
\cline { 3 - 4 } & SD & Jumlah & $\%$ \\
\hline 1 & SMP & 10 & 50,00 \\
2 & SMA & 4 & 20,00 \\
3 & SMA & - & - \\
4 & S1 & 20 & 100 \\
\hline Jumlah & & & \\
\hline
\end{tabular}

Tabel 2 menunjukan tingkat pendidikan petani sampel didaerah penelitian sebagian besar berada pada tingkat SMP (Sekolah Menengah Pertama) yaitu dengan presentase $50,00 \%$, SD (Sekolah Dasar) dengan presentase $30,00 \%$, dan SMA (Sekolah Menengah Atas) dengan presentase $20,00 \%$. 


\section{Jumlah Anggota Keluarga}

Dilihat secara umum, semakin banyak anggota keluarga maka semakin besar jumlah tanggungan yang ditanggung oleh kepala keluarga. Berikut jumlah anggota keluarga dari responden yang merupakan jumlah tanggungan dari kepala keluarga, dapat dilihat pada Tabel 3.

\section{Tabel 3. Jumlah Responden Menurut Jumlah Anggota Keluarga}

\begin{tabular}{ccc}
\hline Anggota & \multicolumn{2}{c}{ Jumlah Responden (Orang) } \\
\cline { 2 - 3 } Keluarga & Jumlah & $\%$ \\
\hline $1-2$ & 7 & 35,00 \\
$3-4$ & 11 & 55,00 \\
$>5$ & 2 & 10,00 \\
\hline Jumlah & 20 & 100 \\
\hline
\end{tabular}

Tabel 3 menunjukan tanggungan anggota keluarga produksi nira aren yaitu gula merah dan captikus dengan keseluruhan 20 petani dari masing-masing pengelolah, dengan jumlah berkisar antara 1-5 orang.

\section{Lamanya Berusaha Menurut Jumlah Responden \\ Cara berusaha tani seseorang sebagian besar dipengaruhi oleh lamanya mereka berusahatani, karena semakin lama mereka melakukan usahatani tersebut semakin dalam pengetahuannya serta semakin luas wawasan petani terhadap usahatani yang dijalankan.}

Tabel 4. Menunjukkan Jumlah Responden Menurut Lamanya Pengalaman Bekerja

\begin{tabular}{ccc}
\hline Lama & \multicolumn{2}{c}{ Jumlah Responden (Orang) } \\
\cline { 2 - 3 } $\begin{array}{c}\text { Berusaha } \\
\text { (Tahun) }\end{array}$ & Jumlah & $\%$ \\
\hline $1-10$ & 9 & 45,00 \\
$11-20$ & 9 & 45,00 \\
$21-30$ & 2 & 10,00 \\
\hline Jumlah & 20 & 100 \\
\hline
\end{tabular}

Tabel 4 menunjukan bahwa lamanya berusaha produksi nira aren pada 1-10 tahun. Sebanyak 9 orang, dan pada 11-20 tahun sebanyak 9, untuk 2 orang responden yang berpengalam lama usaha mulai dari 21-30 tahun.

\section{Penggunaan Sarana Input}

\section{Peralatan Pengolahan Usaha Produk Nira}

Biaya tetap yang dihitung adalah biaya penyusutan peralatan. Peralatan untuk membuat gula merah pada dasarnya menggunakan peralatan seperti parang, pisau, gallon dan wajan. Sedangkan untuk membuat cap tikus peralatannya adalah drum, gallon, pisau, parang, dan peralatan bambu. Namun bambu yang digunakan tidak mengeluarkan biaya. Nilai penyusutan yaitu pengurangan nilai yang disebabkan oleh pemakaian alat selama proses produksi.

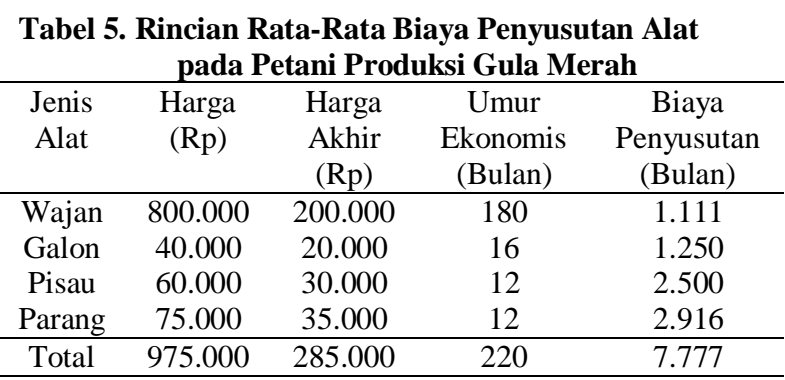

Tabel 4 menunjukan bahwa biaya penyusutan alat yang dikeluarkan setiap adalah untuk wajan Rp.1.111/bulan, biaya penyusutan untuk gallon rata-rata sebesar Rp.1.250/bulan, biaya penyusutan untuk pisau sebesar Rp.2.500/bulan, dan untuk parang Rp.2.916/bulan. Maka dapat disimpulkan bahwa petani yang memproduksi gula merah rata-rata mengeluarkan biaya penyusutan alat sebesar Rp.7.777/bulan.

Tabel 6. Rincian Rata-Rata Biaya Penyusutan Alat pada Petani Produksi Captikus

\begin{tabular}{ccccc}
\hline $\begin{array}{c}\text { Jenis } \\
\text { Alat }\end{array}$ & $\begin{array}{c}\text { Harga } \\
(\mathrm{Rp})\end{array}$ & $\begin{array}{c}\text { Harga } \\
\text { Akhir } \\
(\mathrm{Rp})\end{array}$ & $\begin{array}{c}\text { Umur } \\
\text { Ekonomis } \\
(\text { Bulan) }\end{array}$ & $\begin{array}{c}\text { Biaya } \\
\text { Penyusutan } \\
\text { (Bulan) }\end{array}$ \\
\hline Drum & 150.000 & 75.000 & 6 & 12.500 \\
Galon & 40.000 & 20.000 & 16 & 2.000 \\
Pisau & 60.000 & 30.000 & 12 & 2.500 \\
Parang & 75.000 & 35.000 & 12 & 2.916 \\
\hline Total & 325.000 & 160.000 & 40 & 19.916 \\
\hline
\end{tabular}

Tabel 6 menunjukkan bahwa biaya penyusutan alat adalah untuk pengunaan drum yaitu rata-rata sebesar Rp.12.500/bulan. Biaya penyusutan gallon rata-rata sebesar Rp.2.000/ bulan, Penyusutan pisau sebesar Rp.2.500/bulan, untuk parang biaya penyusutan sebesar Rp.2.916/ bulan. Maka dapat disimpulkan bahwa pengunaan alat mengeluarkan biaya penyusutan sebesar Rp. 
19.916/bulan. Biaya untuk penyusutan peralatan usaha produk nira yaitu gula merah dan captikus tidak menghitung atau menambahkan rumus yaitu biaya dari harga akhir peralatan atau alat.

\section{Bahan Bakar (Kayu Bakar)}

Jenis bahan bakar yang digunakan oleh petani untuk proses memasak gula merah dan captikus adalah kayu bakar. Kayu bakar yang digunakan petani biasanya diperoleh dengan mencari disekitar kebun atau hutan. Petani tidak mengeluarkan biaya untuk membeli bahan kayu bakar karena kayu diambil dari kebun atau hutan yang sudah tidak dipakai.

\section{Bahan Baku}

Bahan baku untuk pembuatan gula merah dan captikus adalah nira aren atau saguer. Nira aren merupakan cairan putih yang keluar dari mayang pohon aren. Umur pohon aren yang dapat menghasilkan nira yang paling baik adalah pada usia 7-15 tahun. Nira sejak keluar dari mayang sudah menghasilkan alkohol dengan kadar rendah dan akan memperoleh hasil mulai dari penyulingan hingga mendapatkan kadar alkohol yang diperlukan untuk pembuatan captikus.

\begin{tabular}{ccccc} 
Tabel 7. Jumlah Responden Produksi Gula \\
\multicolumn{5}{c}{$\begin{array}{c}\text { Merah dan Captikus Berdasarkan } \\
\text { Jumlah Nira yang Digunakan }\end{array}$} \\
\hline \multirow{5}{*}{$\begin{array}{c}\text { Jumlah } \\
\text { Responden }\end{array}$} & $\begin{array}{c}\text { Gula } \\
\text { Merah } \\
\text { (Kg/bulan) }\end{array}$ & $\begin{array}{c}\text { Captikus } \\
\text { (L/bulan) }\end{array}$ & $\begin{array}{c}\text { Gula } \\
\text { Merah } \\
\text { (L/bulan) }\end{array}$ & $\begin{array}{c}\text { Captikus } \\
\text { (L/bulan) }\end{array}$ \\
& \multicolumn{4}{|c}{} \\
\hline 1 & 255 & & 1.020 & \\
1 & 225 & 100 & - & 700 \\
3 & - & 200 & - & 1.400 \\
6 & - & 300 & - & 2.100 \\
4 & - & 400 & - & 2.800 \\
2 & - & 500 & - & 3.500 \\
2 & - & 600 & & 4.200 \\
1 & - & 1.600 & 1.920 & 14.700 \\
\hline Total & 480 & &
\end{tabular}

Untuk gula merah nira aren yang dibutuhkan harus sesuai dengan rasa yang manis pada nira agar saat proses produksi memasak menghasilkan produksi gula merah yang sesuai dengan rasanya yang manis. Tabel 7 Menunjukan bahwa produksi pada gula merah terdapat dua petani penghasil gula merah dengan masing hasil $420 \mathrm{~kg} / \mathrm{bulan}$ dan $375 \mathrm{~kg} / \mathrm{bulan}$. Untuk pengelola produksi cap tikus sebanyak 18 pengusaha dari masing- masing penghasil captikus liter/bulan paling besar 600 liter dengan jumlah petani 1, dan berurut dari 500 liter untuk 2 petani, 400 liter untuk 2 petani, 300 liter untuk 4 petani, 200 liter untuk 6 petani, 100 liter untuk 3 petani pengelolah produk captikus. Maka dapat disimpulkan untuk pengelola gula merah menghasilkan $465 \mathrm{~kg} / \mathrm{bulan}$ untuk 2 pengusaha gula merah dan untuk produksi captikus berjumlah 1600 liter/bulan. Harga nira umumnya di Desa Lolah adalah Rp.2000/liter.

\section{Tenaga Kerja}

Upah tenaga kerja yang di Desa Lolah biasanya dihitung hari kerja atau perhari dalam bekerja untuk satu tenaga kerja atau orang akan memperoleh gaji atau pengeluaran biaya sebesar Rp.100.000 perhari kerja, dapat dilihat dalam Tabel berikut

Tabel 8. Rincian Rata-Rata Biaya Tenaga Kerja Usaha Produk Nira

\begin{tabular}{clrr}
\hline $\begin{array}{c}\text { Jumlah } \\
\text { Responden }\end{array}$ & $\begin{array}{c}\text { Usaha } \\
\text { Nira }\end{array}$ & $\begin{array}{c}\text { Tenaga } \\
\text { Kerja } \\
\text { (Bulan) }\end{array}$ & $\begin{array}{c}\text { Biaya } \\
\text { Tenaga } \\
\text { Kerja } \\
\text { (Rp/Bulan) }\end{array}$ \\
\hline 2 & Gula Merah & 30 & 3.000 .000 \\
3 & Captikus & 4 & 400.000 \\
6 & Captikus & 8 & 800.000 \\
4 & Captikus & 12 & 1.200 .000 \\
2 & Captikus & 16 & 1.600 .000 \\
2 & Captikus & 20 & 2.000 .000 \\
1 & Captikus & 24 & 2.400 .000 \\
\hline Jumlah & & 114 & 11.400 .000 \\
\hline
\end{tabular}

Tabel 8 menunjukkan bahwa biaya tenaga kerja usaha produk nira di Desa Lolah Rp.11.400.000/Bulan dengan 20 responden pengusaha produk nira, dengan upah tenaga kerja Rp.100.000/hari.

\section{Transportasi}

Untuk memudahkan serta membantu petani saat bekerja petani menggunakan alat transportasi dalam menyalurkan hasil produksi baik itu gula merah atau captikus petani menggunakan fasilitas kendaraan bermotor dan roda sapi. Semua pengelola nira aren baik itu gula merah dan captikus menggunakan kedua alat transportasi yaitu roda sapi dan sepeda motor, karena memakai sepeda motor maka mengeluarkan biaya untuk pembelian bensin selama waktu kerja untuk produksi gula merah untuk 1 bulan yaitu 30 hari dengan biaya perhari bensin Rp.8.000 dengan total setiap bulan Rp. 224.000 dan untuk captikus mengeluarkan biaya transportasi pada saat tiap kali produksi yaitu 
dengan masing-masing pengolah mulai dari 4-24 hari kerja setiap bulan dengan biaya Rp.32.000 sampai Rp.192.000 dari masing pengolah captikus.

\section{Harga Jual}

Harga jual merupakan salah satu variabel penting yang menentukan besarnya penerimaan dari usaha produksi gula merah serta captikus. Harga sangat mempengaruhi besarnya penerimaan, produksi usaha untuk gula merah menghasilkan $480 \mathrm{~kg} /$ bulan untuk produksi dua pengelola gula merah dengan harga jual yang ditawarkan sesuai dengan tingkat harga yang ada dipasaran dengan harga Rp.30.000/kg. Sedangkan untuk hasil produksi dari captikus mulai dari 100600 liter/bulan untuk masing-masing pengolah dihargai sesuai harga yang berlaku perliter Rp.24.000.

\section{Penerimaan}

Penerimaan usaha produksi gula merah dan captikus tergantung pada jumlah produksi dan harga jual dari usaha produksi baik gula merah dan cap tikus. Penerimaan merupakan perkalian antara produksi dengan harga jual yang di terima petani.

\begin{tabular}{|c|c|c|c|c|}
\hline \multirow{2}{*}{ Produksi } & \multirow{2}{*}{$\begin{array}{c}\text { Total } \\
\text { Produksi/Bulan }\end{array}$} & \multicolumn{2}{|c|}{ Harga Jual Produksi } & \multirow[b]{2}{*}{$\begin{array}{c}\text { Rata- } \\
\text { RataTotal } \\
\text { Penerimaan }\end{array}$} \\
\hline & & $\begin{array}{c}\text { Gula } \\
\text { Merah } \\
\text { /Kg }\end{array}$ & $\begin{array}{c}\text { Cap } \\
\text { Tikus/Liter }\end{array}$ & \\
\hline $\begin{array}{l}\text { Gula } \\
\text { Merah }\end{array}$ & 480 & 30.000 & & 7.200 .000 \\
\hline $\begin{array}{l}\text { Cap } \\
\text { Tikus }\end{array}$ & 5.100 & & 24.000 & 6.800 .000 \\
\hline
\end{tabular}

Pengolah Produksi gula merah sebanyak $480 \mathrm{~kg}$ perbulan dengan harga jual Rp.30.000/kg dengan total penerimaan Rp.14.400.000/bulan, untuk penerimaan rata-rata setiap pengusaha sebesar Rp.7.200.000. Pengelolah produksi captikus sebanyak 5.100 liter dengan harga jual Rp.24.000/liter dengan total penerimaan perbulan Rp.122.400.000, untuk penerimaan rata-rata setiap pengusaha sebesar Rp.6.800.000.

\section{Biaya Produksi}

Biaya produksi adalah seluruh pengeluaran untuk membiayai proses produksi dalam usaha. Biaya yang dihitung dalam penelitian ini adalah semua biaya yang dikeluarkan oleh pengelolah adalah biaya tetap berupa biaya tetap yaitu biaya penyusutan alat dan biaya variabel berupa biaya transportasi. bahan baku, tenaga kerja.

Tabel 10. Biaya Variabel Gula Merah dan Captikus

\begin{tabular}{ccc}
\hline Biaya Variabel & Gula Merah & Captikus \\
\hline Bahan Baku & 1.590 .000 & 1.983 .333 \\
Tenaga Kerja & 3.000 .000 & 1.133 .333 \\
Transportasi & 240.000 & 90.666 \\
\hline Total & 4.830 .000 & 3.207 .333 \\
\hline
\end{tabular}

Tabel 10 Menunjukan bahwa untuk biaya variabel produksi gula merah yaitu untuk biaya bahan baku dengan total dua pengolah sebesar Rp.3.180.000/bulan, dengan rata-rata Rp.1.590.000/bulan, produksi captikus untuk total 18 pengolah biaya bahan baku sebesar Rp.35.700.000/bulan dengan rata-rata Rp.1.983.333/bulan. Biaya Tenaga kerja untuk produksi gula merah yaitu sebesar Rp.6.000.000/bulan dan rata-rata Rp.3.000.000/bulan, untuk produksi captikus untuk tenaga kerja sebesar Rp.20.400.000/bulan dan rata-rata Rp.1.133.333. Biaya Transportasi untuk produksi gula merah sebesar Rp.480.000/bulan dengan rata-rata Rp.240.000/bulan, untuk captikus biaya transportasi sebesar Rp.1.632.000/bulan dengan rata-rata Rp.90.666/bulan. Total keseluruhan untuk biaya rata-rata produksi gula merah sebesar Rp. 4.830.000/bulan, dan untuk captikus sebesar Rp. 3.207.333/bulan.

\section{Tabel 11. Biaya Produksi Gula Merah dan Captikus}

\begin{tabular}{ccc}
\hline Jenis Biaya & \multicolumn{2}{c}{ Rata-Rata Produksi Usaha } \\
\cline { 2 - 3 } & Gula Merah & Captikus \\
\hline $\begin{array}{c}\text { Biaya Tetap } \\
\text { Penyusutan }\end{array}$ & 7.777 & 19.916 \\
Biaya Variabel & & \\
& 4.830 .000 & 3.207 .333 \\
\hline $\begin{array}{c}\text { Total Biaya } \\
\text { Produksi }\end{array}$ & 4.837 .777 & 3.227 .249 \\
\hline
\end{tabular}

Tabel 8 Menunjukan bahwa rata-rata jumlah biaya produksi mulai dari gula merah berjumlah Rp.4.837.777/bulan dan produksi biaya rata-rata captikus berjumlah Rp.3.227.249/bulan. 


\section{Pendapatan}

Tinggi rendah pendapatan ditentukan oleh penerimaan yang diperoleh petani. Pendapatan usaha adalah hasil dari pengurangan antara total penerimaan dengan total biaya produksi yag dikeluarkan setiap petani dari tahap persiapan hingga transportasi hasil produksi. Tabel 10 Menunjukan pendapatan usaha produksi gula merah dan captikus.

\section{Tabel 12. Pendapatn Usaha Produksi Gula Merah dan Captikus}

\begin{tabular}{cccc}
\hline Produksi/Usaha & Penerimaan & $\begin{array}{c}\text { Biaya } \\
\text { Produksi }\end{array}$ & Pendapatan \\
\hline Gula Merah & 7.200 .000 & 4.837 .777 & 2.724 .446 \\
Captikus & 6.800 .000 & 3.227 .249 & 3.572 .751 \\
\hline
\end{tabular}

Tabel 9 Menunjukan bahwa pendapatan usaha produksi nira aren yaitu gula merah untuk rata-rata penerimaan per petani Rp.7.200.000 dikurangi dengan biaya produksi Rp.4.837.777 maka didapat pendapatan usaha produksi untuk gula merah Rp.2.724.446, sedangkan untuk pendapatan captikus rata-rata penerimaan Rp.6.800.000 dikurangi biaya produksi Rp.3.227.249 maka didapat pendapatan Rp.3.572.751.

\section{KESIMPULAN DAN SARAN}

\section{Kesimpulan}

Berdasarkan penelitian ditemukan bahwa produksi nira aren di Desa Lolah dijadikan usaha yaitu gula merah dan captikus, rata-rata pendapatan setiap pengusaha dari usaha gula merah sebesar Rp.2.724.446 dan untuk produksi captikus setiap pengusaha sebesar Rp.3.572.751. Jumlah keseluruhan pendapatan hasil produksi nira dapat diperoleh dengan menambahkan hasil produksi gula merah dan captikus yaitu secara keseluruhan sebesar Rp.6.297.197.

\section{Saran}

Usaha produksi nira aren ini sebaiknya dikembangkan karena dapat membantu para petani untuk meningkatkan pendapatan dan memenuhi kebutuhan keluarga. Bagi Pemerintah dan masyarakat adanya kerja sama untuk turut ambil bagian memperhatikan apa yang menjadi usaha masyarakat petani terutama pengolah nira aren untuk dapat dijadikan usaha ini lebih berkembang dan maju baik dari pohon aren dapat dipertahankan dan dilestarikan untuk menjaga lingkungan alam dan menjadi potensi hasil nira aren sampai pada hasil produksi nira yang menghasilkan pendapatan serta keuntungan bagi masyarakatnya. Adanya penelitian ini dapat menjadi bahan acuan untuk pengembangan ilmu kedepan baik menjadi bahan bacaan ataupun informasi.

\section{DAFTAR PUSTAKA}

Ahmed Riahi Belkaoui. 2006. Accounting Theory. Salemba Empat. Jakarta.

Assauri, Sofyan. 2012. Manajemen Pemasaran.

Rajawali Gramedia Pustaka Utama. Jakarta.

Boediono. 2002. Pengantar Ilmu Ekonomi No.1 (Ekonomi Mikro). BPFE. Yogyakarta.

Fatriani, Sunardi, Ferry, Prayudi NS. 2012. Pengaruh Umur Pohon Aren (Arenga pinnata MERR) Terhadap Produksi Nira di Desa Pulantan Kecamatan Awayan Kabupaten Balangan Provinsi Kalimantan Selatan. Jurnal Hutan Tropis. Program Studi Kehutanan Fakultas Kehutanan Universitas Lambung Mangkurat.

Harahap, Sofyan, Syafri. 2001. Analisis Kritis atas Laporan Keuangan. Raja Grafindo Persada. Jakarta.

Harahap, Sofyan. 2001. Sistem Pengawasan Manajemen. Quantum. Jakarta.

Harris, T, N. 1994. Devlomental and Germination Studies Of The Sugar Palm (Arengga Pinnata Merr.) Seed. Phd Thesis, University Putra Malaysia.

Henderson, A. 2009. Palms of Southern Asia. New York Botanical Garden.

Henry Sarnowo dan Danang Sunyoto. 2013. Pengantar Ilmu Ekonomi Mikro PT. Buku Seru, Yogyakarta.

Kadariah. 2002 Analisis Pendapatan Nasional. Bina Aksara, Jakarta.

Lampiran Peraturan Menteri Pertanian Republik Indonesia Nomor 133/Permentan/OT 140/12/2013 Tentang Pedoman Budidaya Aren (Arengapinnata MERR) yang baik. 2014, No 17

Lasut, T, Marthen. 2012. Budidaya yang baik Aren (Arenga pinnata Wurmb Merr.). Jurnal Kerjasama Fakultas Pertanian Universitas Sam Ratulangi dan Universitas Texas A \& M. 